\title{
Catalog Number
}

National Cancer Institute

\section{Source}

National Cancer Institute. Catalog Number. NCI Thesaurus. Code C99286.

The identifier assigned to a product, usually in the list of products published by a reseller or manufacturer. 